\title{
Redes Sociais de Apoio as famílias de prematuros que vivenciam a hospitalização: Um estudo Transcultural
}

\author{
Social Networks Supporting premature families living in hospitalization: A Transcultural \\ study \\ Redes Sociales de Apoyo a las familias prematuras que viven en la hospitalización: Un \\ estudio Transcultural
}

Ana Celi Silva Torres Nascimento ${ }^{1 *}$, Aisiane Cedraz Moraes ${ }^{1}$, Rita da Cruz Amorim ${ }^{1}$, Sinara de Lima Souza ${ }^{1}$.

\section{RESUMO}

Objetivo: Analisar as redes sociais de apoio familiar no enfrentamento da internação do recém-nascido prematuro em Unidade de Terapia Intensiva Neonatal à luz da Teoria Transcultural. Métodos: Estudo qualitativo, descritivo e exploratório. Foram realizadas observação participante e entrevistas semiestruturadas com dezesseis (16) familiares de recém-nascidos internados na unidade neonatal de uma maternidade pública no interior baiano, nos meses de maio e junho de 2019. Utilizou-se o software Interface de $R$ pour analyses Multidimensionnelles de Textes et de Questionnaire ${ }^{\circledR}$ e Análise de Conteúdo de Bardin para análise dos dados. O estudo foi aprovado por Comitê de Ética em Pesquisa. Resultados: A partir da análise de dados foi possível perceber a importância das redes sociais de apoio familiar, dentre elas, o próprio amor materno, a família ampliada, os profissionais de saúde e a espiritualidade durante todo o processo de hospitalização. Conclusão: Conhecer a estrutura familiar, o seu contexto social, cultural e econômico, incluindo sua rede social de apoio, são elementos indissociáveis para realização de uma assistência de integral e eficaz para o prematuro e a sua família.

Palavras-chave: Apoio Social, Família, Recém-nascido prematuro, Hospitalização, Enfermagem Transcultural.

\begin{abstract}
Objective: To analyze family support social networks in coping with premature newborn hospitalization in a Neonatal Intensive Care Unit in the light of Transcultural Theory. Methods: Qualitative, descriptive and exploratory study. Participant observation and semi-structured interviews were conducted with sixteen (16) family members of newborns admitted to the neonatal unit of a public maternity hospital in the interior of the state of Bahia, in May and June 2019. It was used the R interface software for Multidimensionnelles analysis. Textes et de Questionnaire ${ }^{\circledR}$ and Bardin Content Analysis for data analysis. The study was approved by the Research Ethics Committee. Results: From the data analysis it was possible to realize the importance of family support social networks, among them, the mother's own love, the extended family, health professionals and spirituality throughout the hospitalization process. Conclusion: Knowing the family structure, its social, cultural and economic context, including its social support network, are inseparable elements for the realization of comprehensive and effective care for the premature and his family.
\end{abstract}

Key words: Social Support, Family, Premature Newborn, Hospitalization, Transcultural Nursing.

\footnotetext{
1Universidade Estadual de Feira de Santana (UEFS), Feira de Santana-Bahia.

*E-mail: celitorres19@hotmail.com

Pesquisa Financiada pela Fundação de Amparo à Pesquisa do Estado da Bahia (FABESB). Edital 003/2017, por meio de bolsa de Mestrado.
} 


\section{RESUMEN}

Objetivo: Analizar las redes sociales de apoyo familiar para hacer frente a la hospitalización prematura de recién nacidos en una unidad de cuidados intensivos neonatales a la luz de la teoría transcultural. Métodos: Estudio cualitativo, descriptivo y exploratorio. La observación participante y las entrevistas semiestructuradas se llevaron a cabo con dieciséis (16) miembros de la familia de recién nacidos ingresados en la unidad neonatal de un hospital público de maternidad en el interior del estado de Bahía, en mayo y junio de 2019. Se utilizó el software de interfaz R para el análisis multidimensional. Textes et de Questionnaire ${ }^{\circledR}$ y Bardin Content Analysis para análisis de datos. El estudio fue aprobado por el Comité de Ética en Investigación. Resultados: Del análisis de datos fue posible darse cuenta de la importancia de las redes sociales de apoyo familiar, entre ellas, el amor de la madre, la familia extendida, los profesionales de la salud y la espiritualidad durante todo el proceso de hospitalización. Conclusión: Conocer la estructura familiar, su contexto social, cultural y económico, incluida su red de apoyo social, son elementos inseparables para la realización de una atención integral y efectiva para el prematuro y su familia. Además, se enfatiza la importancia de valorar la red de apoyo social de cada familia durante el proceso de hospitalización.

Palabras clave: Apoyo social, familia, recién nacido prematuro, hospitalización, enfermería transcultural.

\section{INTRODUÇÃO}

A família é a instituição social mais antiga da sociedade, e tem passado por diversas transformações ao longo do tempo. Hoje é considerado um sistema dinâmico, sendo possível ver diferentes configurações familiares, incluindo, além da família nuclear, tios, avós, padrinhos, amigos e outros grupos sociais, como: serviços de saúde, o credo religioso e/ou político (PEREIRA NETO EF, et al., 2016).

As pessoas convivem por um determinado tempo, unidas por laços de consanguinidade e/ou afetividade, com direitos e responsabilidades, vivendo em um determinado ambiente e influenciado por suas crenças, costumes e visão de mundo, sendo caracterizada pela diversidade, justificada pela incessante busca pelo amor e felicidade (BIROLI F, 2014).

A prevalência da prematuridade é crescente no mundo, principalmente em países industrializados e configura-se uma questão de saúde pública, tento em vista uma estimativa para 2030 de uma alta mortalidade no período neonatal, com complicações do nascimento prematuro (LIU L, et al., 2015)

Um nascimento prematuro e a sua hospitalização em uma Unidade de Terapia Intensiva Neonatal (UTIN) é uma experiência marcante que gera angústia e sofrimento a família, e que altera a sua dinâmica de funcionamento (SANTANA JO, et al., 2017). A unidade neonatal possibilita um atendimento diferenciado ao recém-nascido $(R N)$ devido as suas especificidades e pelos seus recursos físicos, materiais e profissionais de saúde especializados, logo contribui para o tratamento e auxilia na redução da mortalidade dos neonates (COSTA R, PADILHA MI, 2012).

Porém, a medicina neonatal não pode ser prioritariamente a alta tecnologia, focalizando na doença e no procedimento; devendo incluir também fatores humanos, onde o bebê hospitalizado não deve estar rodeado apenas de aparelhos muito bons e equipe altamente qualificada, mas ter garantida da participação da família no planejamento e na tomada de decisão na assistência ao prematuro, com suporte da sua rede social de apoio (SILVA LJ, et al., 2009).

Neste contexto, rede social é um conjunto de seres humanos que interagem entre si de forma constante, com quem se desenvolve diálogo e que nos torna verdadeiros. São relações que envolvem vínculos interpessoais ampliados, incluindo as relações que são estabelecidas na comunidade, incluindo anto as relações íntimas como as ocasionais (BRASIL, 2017).

Compreender as questões da prematuridade com o auxílio da concepção de rede social de apoio, possibilita identificar a teia de interações estabelecidas frente à situação de crise e o modo como as pessoas lidam com esta experiência. Nesta perspectiva, a prematuridade pode ser vista como um processo complexo que envolve vários aspectos: os biológicos/clínicos próprios de cada criança; a relação com os pais e 
familiares e os diversos ambientes nos quais participam, como os serviços de saúde e as intervenções dos profissionais de saúde (CUSTÓDIO ZA, et al., 2014; HENCKEMAIER L, et al., 1014).

Baseado em Leininger, a enfermeira deve estar capacitada para atender o prematuro e sua família de forma integral, respeitando os aspectos culturais das necessidades humanas de cada família para desenvolver um cuidado culturalmente congruente, onde as culturas do $\mathrm{RN}$ e de seus familiares estarão presentes em todo o processo assitencial (HENCKEMAIER L, et al., 1014).

A partir do exposto, o estudo tem com objetivo analisar as redes sociais de apoio familiar no enfrentamento da internação do recém-nascido prematuro em Unidade de Terapia Intensiva Neonatal à luz da Teoria Transcultural.

\section{MÉTODOS}

Estudo qualitativo, descritivo e exploratório, baseado na Teoria Transcultural de Leininger; considerando os passos recomendados pelos Critérios Consolidados para Relatar uma Pesquisa Qualitativa (COREQ). Neste estudo, foi classificada a família como uma unidade ampliada e dinâmica, considerando pessoas próximas como membros da família (avôs, primos, amigos e vizinhos) (PEREIRA NETO EF, et al., 2016). Foram desenvolvidas 16 entrevistas com familiares de prematuros internados na UTIN de uma maternidade pública do interior baiano.

Os critérios de inclusão adotados foram: famílias de RN pré-termos; internados na UTIN há pelo menos sete dias, considerando ser um tempo ideal de convivência que possibilite responder ao questionamento do objeto de estudo. A faixa etária dos participantes foram pais e mães adolescentes com a idade igual ou superior a 15 anos; e membros da família contemporânea acima dos 18 anos. Como critério de exclusão, estabeleceu-se: famílias de prematuros que tivesse associado alguma má-formação congênita.

Para a coleta de dados foram utilizadas as técnicas de observação participante e a entrevista semiestruturada, com duração média de 7 a 18 minutos, entre o período de maio e junho de 2019. Ressaltase que as entrevistas realizadas foram gravadas com a utilização de aparelho eletrônico/digital. Para manter a preservação da identidade dos participantes, os fragmentos de cada familiar entrevistado aparecerão codificados pela sequência da letra $E$, seguida de no número arábico tradutor da ordem de entrevista desenvolvida no estudo.

Os dados foram avaliados pelo método de Análise de Bardin, levando em consideração a análise de conteúdo, onde a técnica consta de três grandes fases, a saber: a pré-análise, a exploração do material e o tratamento dos resultados obtidos e interpretação (BARDIN L, 2016).

Para complementar a análise de conteúdo de Bardin, que consiste em uma leitura aprofundada de cada uma das respostas objetivando a visão do todo, foi utilizado o software denominado Interface de $R$ pour analysesMultidimensionnelles de Textes et de Questionnaires ${ }^{\circledR}$ (IRAMUTEQ). Um programa que permite a análise do todo e posterior visão das partes, isto é, de cada palavra do texto ainda que de forma não isoladas, através de processos automáticos que associam a matemática e a estatística (CAMARGO BV, JUSTO AM., 2018).

Das análises de dados textuais oferecidas por esse software, optou-se por: "Classificação (método de Reinert)". Neste tipo de análise, os seguimentos de texto (ST) são classificados em função dos seus respectivos vocabulários, e o conjunto deles é repartido em função da presença ou ausência de similaridade entre as sentenças. A partir de matrizes de cruzando ST e formas reduzidas, aplica-se o método de Classificação Hierárquica Descendente (CHD) e obtém-se uma classificação definida (CAMARGO BV, JUSTO AM., 2018; SOUZA MAR, et al., 2018).

Todos os participantes assinaram os devidos Termos de Consentimento e a pesquisa foi aprovada pelo Comitê de Ética e Pesquisa segundo o parecer $n^{\circ}$ 3.218.290/2019 (CAAE: 06704919.6.0000.0053). Sendo respeitadas as exigências formais contidas nas normas nacionais e internacionais, seguindo as recomendações para a pesquisa com seres humanos da Resolução 466/2012. 


\section{RESULTADOS}

Dezesseis familiares (Tabela 1) participaram do estudo: 14 mães, 1 pai e 1 vizinho/amigo da família, com idade variando entre dezessete (17) a quarenta e seis (46) anos. Sobre o estado civil, oito (8) eram solteiros, três (3) declararam-se casados, quatro (4) em união consensual e uma (1) mulher divorciada. Referentes à localização, oito (8) moravam em Feira de Santana e oito (8) pertenciam a outros municípios. Em relação à renda familiar, dez (10) informaram ter renda mensal de um salário mínimo, três (3) possuíam renda acima de um salário mínimo, um (1) possuía o auxílio da bolsa família e o benefício do esposo e um (1) dependia da bolsa família. Quanto à religião, oito (8) declararam serem católicos, quatro (4) protestantes e quatro (4) sem religião; porém, afirmaram acreditar em Deus.

Ao utilizar o software IRAMUTEQ, a CHD permitiu gerar o dendrograma abaixo, onde ilustra a obtenção de seis (6) classes. Nestas, os ST foram interpretados e posteriormente as classes foram agrupadas em quatro categorias, sendo elas: $\mathrm{O}$ amor materno como eixo das redes de apoio para enfrentamento da prematuridade; a família ampliada como suporte parental; profissionais de saúde no apoio a família; e a espiritualidade no suporte a família.

Para a composição destas categorias, seguiu-se a seguinte ordem: a primeira categoria emergiu da classe 1, a segunda das classes 2 e 6, a terceira da classe 3, e a última categoria, das classes 4 e 5, sendo estas apresentadas no dendrograma, que é a representação gráfica proveniente da análise feita pelo software (Figura 1), o qual mostra o percentual de ST por classe.

Tabela 1 - Caracterização das Famílias participantes da pesquisa. Feira de Santana-BA, Brasil, 2019.

\begin{tabular}{|c|c|c|c|c|c|c|}
\hline Identificação & Idade & Sexo & Religião & Renda Familiar & Naturalidade & Estado civil \\
\hline E1 & 27 & Fem. & Protestante & 1 salário minimo & $\begin{array}{l}\text { Feira de } \\
\text { Santana }\end{array}$ & Casada \\
\hline E2 & 25 & Fem. & $\begin{array}{l}\text { Acredita } \\
\text { em Deus }\end{array}$ & Bolsa família & $\begin{array}{l}\text { Feira de } \\
\text { Santana }\end{array}$ & Solteira \\
\hline E3 & 23 & Fem. & $\begin{array}{l}\text { Acredita } \\
\text { em Deus }\end{array}$ & 1 salário minimo & $\begin{array}{c}\text { Teodoro } \\
\text { Sampaio-Ba }\end{array}$ & $\begin{array}{l}\text { União } \\
\text { estável }\end{array}$ \\
\hline E4 & 46 & Masc. & Católico & >1 salário minimo & $\begin{array}{l}\text { S. Terezinha } \\
\text { Mora em Feira }\end{array}$ & Solteiro \\
\hline E5 & 22 & Fem. & $\begin{array}{l}\text { Acredita } \\
\text { em Deus }\end{array}$ & 1 salário minimo & $\begin{array}{l}\text { Feira de } \\
\text { Santana } \\
\end{array}$ & $\begin{array}{l}\text { União } \\
\text { estável }\end{array}$ \\
\hline E6 & 23 & Fem. & Católica & 1 salário minimo & Bonito-Ba & $\begin{array}{l}\text { União } \\
\text { estável }\end{array}$ \\
\hline E7 & 37 & Masc. & $\begin{array}{l}\text { Acredita } \\
\text { em deus }\end{array}$ & 1 salário minimo & Bonito-Ba & Solteito \\
\hline E8 & 17 & Fem. & Protestante & 1 salário minimo & $\begin{array}{c}\text { Valente } \\
\text { Mora em Feira }\end{array}$ & Solteira \\
\hline E9 & 30 & Fem. & Protestante & $\begin{array}{c}\text { Bolsa família+ } \\
\text { Benéfício }\end{array}$ & Biritinga & Casada \\
\hline E10 & 24 & Fem. & Católica & 1 salário minimo & $\begin{array}{l}\text { Feira de } \\
\text { Santana }\end{array}$ & Casada \\
\hline E11 & 38 & Fem. & Católica & <1 salário minimo & $\begin{array}{l}\text { Feira de } \\
\text { Santana }\end{array}$ & Divorsiada \\
\hline E12 & 21 & Fem. & Católica & 1 salário minimo & Salvador & Solteira \\
\hline E13 & 37 & Fem. & Católica & 1 salário minimo & Cachoeira & $\begin{array}{l}\text { União } \\
\text { estável }\end{array}$ \\
\hline E14 & 21 & Fem. & Protestante & > 1 salário minimo & $\begin{array}{c}\text { São Paulo } \\
\text { Mora em Feira }\end{array}$ & Solteira \\
\hline E15 & 22 & Fem. & Catolica & $>1$ salário minimo & Tucano & Solteira \\
\hline E16 & 29 & Fem. & Catolica & 1 salário minimo & $\begin{array}{c}\text { Riachão de } \\
\text { Jacuípe }\end{array}$ & Solteira \\
\hline
\end{tabular}

Fonte: Nascimento ACST, et. al., 2019. 
Figura 1 - Dendrograma da Classificação Hierárquica Descendente do corpus "redes de apoio" (forma horizontal). Feira de Santana-BA, Brasil, 2019.
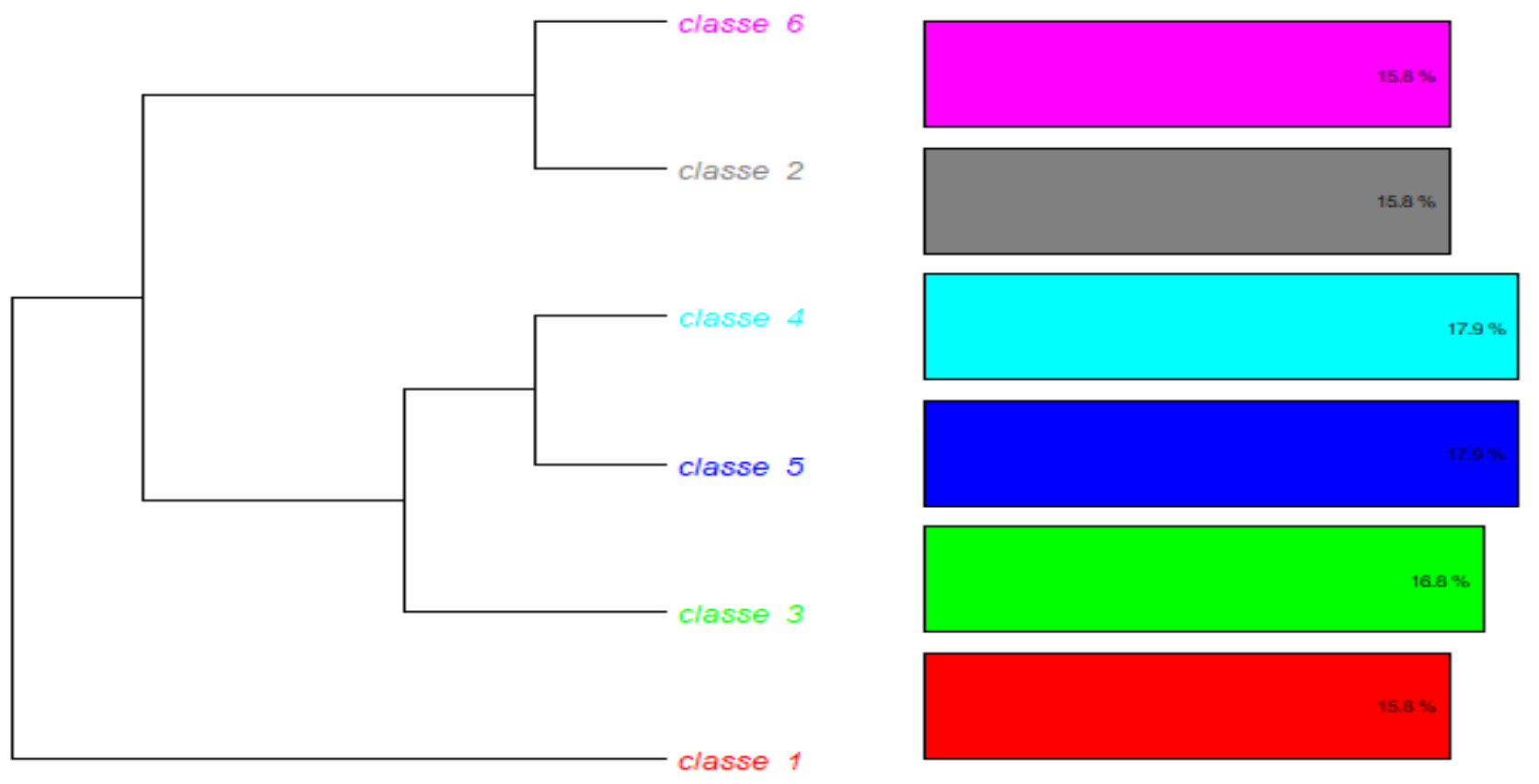

Fonte: Nascimento ACST, et. al., 2019.

As categorias temáticas resultantes da análise das classes, bem como as falas dos entrevistados, são representadas a seguir:

\section{$\mathrm{O}$ amor materno como eixo das redes de apoio para enfrentamento da prematuridade}

Nesta categoria, ressalta-se a importância dos sentimentos maternos como o amor incondicional ao filho prematuro, que são experienciados antes do internamento do filho na unidade neonatal. Esse amor fortalece a própria mãe e a ajuda para organizar suas redes de apoio e vivenciar a hospitalização do filho prematuro:

“(...) O amor pelo meu filho, e eu sei que tenho e que está forte por ele. Se eu desmoronar, ele também vai se sentir fraco" (E1).

"(...) O amor que sinto pelo meu filho, eu amo tanto ele que acho que o tempo que eu passar aqui, ele estando bem para mim, não importa" (E2).

“(...) Amor que a gente desde o princípio, quando a gente tá grávida, né! Já tem um amor de mãe ali, que só nós que somos mãe, sabemos o que isso significa" (E9).

Foi observado e registrado em diário de campo que algumas mães são influenciadas pela sua cultura e visão de mundo, marcadas pelo modelo patriarcal e acham que são detentoras e geradoras do cuidado, assumindo "sozinhas" a maternidade, apesar dos companheiros e familiares quererem se envolver, elas limitam sua participação (CUSTODIO N, et al., 2013). Além de apresentar resistência ao apoio oferecido pela equipe de saúde:

“(...) Eu mesma, quase ninguém me ajuda (...). Se eu não chegar lá e perguntar, falar alguma coisa. Se eu não chamar atenção, eu não sei de nada..." (E6).

“(...) Eu acho mesmo que se não tivesse ninguém, eu estaria aqui [na UTIN] firme viu” (E14).

\section{A família ampliada como suporte parental}

Diante da prematuridade, é fundamental conhecer os recursos pessoais que cada família dispõe e como esses recursos podem interferir de forma positiva no enfrentamento e na superação desta situação; além, de 
servirem como fatores de proteção para o desenvolvimento desses RN. Em relação à rede social pessoal os pais, buscam forças nas pessoas em que percebem como significativas, como os membros da família extensa, vizinhos, amigos, capazes de aportar um apoio duradouro e de qualidade:

“(...) Minha família toda sempre me apoiando (...). Todos são iguais porque quando meu marido não vem, vem minha irmã, minha tia, minha outra irmã, sempre assim, um reversando com o outro" (E2).

“(...) Minha família toda são presentes. Tanto a minha quanto a dele. Presentes $o$ tempo todo Quando não vem sempre liga, pergunta como está quando não dá pra vir" (E5).

“(...) Minha família muito importante pra mim. Eles estão me ajudando muito neste momento, ontem teve minha tia mesmo (...). Ela veio me dando uma maior força" (E12).

Outros achados apontados que é algo que dificulta a participação da rede social no apoio aos pais, é a distância geográfica e falta de recursos econômicos e sociais, evidenciando os elementos do segundo nível do modelo SUNRISE de Leininger, que influenciam no cuidado individual e familiar (MORAIS AC, CAMARGO CL., 2017). Assim, observou-se a baixa frequência de visitas aos recém-nascidos e as mães na forma presencial, porém as famílias buscam outras formas de reorganização, comunicação e suporte emocional:

"(...) Tenho do meu esposo, da minha sogra. Minha mãe, porque não mora aqui, mas sempre tenho contato [por telefone] com minha mãe, meus irmãos" (E9).

“(...) Minha família me apoia. Não está comigo todo momento porque todo mundo trabalha e a distância também, mas sempre final de semana vem um me visitor" (E13).

“(...) A minha família sempre vem me ver, quase todos os dias, minha irmã, minha mãe, vem me ver (...). Minha mãe é de lá também, mas enquanto estou aqui, ela está na casa de minha irmã pra ficar me dando um suporte" (E8).

Outra situação evidente que emergiu relaciona-se ao funcionamento da UTIN e as suas normas e rotinas rígidas, que dificultam uma presença mais efetiva da rede de apoio dentro do ambiente neonatal, que poderia colaborar com uma maior formação de vínculo entre o RN e os seus membros familiares, abrangendo amigos, vizinhos e outros membros da comunidade que são significativas para as famílias:

“(...) Porque é uma visita por dia, né. São só cinco minutinhos (...). Pra mim é muito importante porque você se sente assim, acolhida, né. Então, você não sente que não está sozinho. Pra mim é muito importante. E eu acho que pra ele [bebê] é muito importante" (E15).

\section{Profissionais de saúde no apoio à família}

Para enfrentar a prematuridade e a hospitalização, os pais buscam conhecer os recursos institucionais disponíveis para eles e para a sua criança, que diz respeito à rede social de apoio oferecida pelos serviços de saúde disponível na instituição hospitalar. Procuram identificar quem da equipe cuida com afeição e doçura, podendo inferir positivamente no crescimento e desenvolvimento do seu bebê:

"(...) As equipes lá são todas gente boa. Cuida bastante da minha filha, né! São muito atenciosos" (E10).

"(...) As enfermeiras, as técnicas de enfermagem. Porque tipo tem umas que é mais fechadinhas, normal, né. Nem todo mundo é espontâneo e aberto, mas tem outras, a maioria delas mesmo, elas conversam comigo. Me dá conselho. Me acalma lá dentro" (E12).

Algumas entrevistadas ressaltaram a importância do compartilhamento das informações oferecidas pelos profissionais de saúde à família, para mantê-las informadas sobre funcionamento e rotina da UTIN. Além de ajudar numa melhor compreensão do prematuro que necessita de hospitalização prolongada e de cuidados 
especiais. Esses cuidados e orientações dispensados a família são também referenciados por Leininger ao analisar os modos de cuidar, como os fatores sociais, educacionais e de inter-relacionamentos:

“(...) Quando se tem algum médico eles chegam, falam alguma coisa, mas quem mais fica lá, quem sempre me dá [informações], são as enfermeiras, fisioterapeutas (...) o psicólogo" (E1).

“(...) Então, eu acho que foi importante ela ter conversado comigo, me explicado as coisas e porque ai eu fiquei já ciente tipo do iria acontecer. Eu não tive tipo uma expectativa frustrada" (E8).

\section{A espiritualidade no suporte da família do prematuro}

A prematuridade e suas peculiaridades provocam instabilidade emocional nas famílias; que se intensificam com notícias de piora do quadro clínico; e incentivadas a partir da melhora destes. Nesta categoria, a fé é demonstrada como base para vivenciar a situação instalada, e com o passar do tempo a esperança é renovada e fortalecida:

“(...) Deus deu muita força a gente, porque eu não esperava que meu filho sair. Mas, graças a Deus, Deus falou que era para eu confiar nele que ele garantia" (E2).

“(...) Se não fosse Deus eu estava nem sei o que teria acontecido, já estava louca já. Me apego muito a Deus. Eu só estou forte aqui, é Deus que está me dando forces" (E6).

“(...) Ah, a fé em Deus, tenho muita fé em Deus (...) em Deus que vai dar tudo certo. Então, é o que mantém a gente segura, sabe firme. Porque senão a gente acaba desabando" (E15).

Outro aspecto relatado por alguns familiares e que mostra algo também referenciado por Leininger, são os fatores religiosos que influenciam na experiência da hospitalização de modo menos traumático, onde o poder da oração fortalece e revigora a família (HENCKEMAIER L, et al., 2014).

“(...) Deus me deu muita força. Eu oro muito, a melhoria de meu filho e de muitos que esta ali dentro, eu creio que vai sair todo mundo de lá de dentro. Estou indo na igreja" (E2).

“(...) Na igreja também oram bastante pra ele (...). Se ele chegou até aqui ele é promessa, então” (E14).

“(...) Eu peço a Deus. Eu oro lá dentro, peço a Deus bastante. Pela a vida dela, pela saúde" (E16).

\section{DISCUSSÃO}

A unidade familiar apresenta características modernas, onde a visão do modelo nuclear e patriarcal de família ainda existem, mas há uma nova concepção de família. Modelo esse que possui jeito próprio de se estruturar conforme as suas necessidades, forma específica de se inter-relacionar, se comunicar e se emocionar, com suas próprias regras e culturas (VIERA CS, et al., 2010).

A composição do universo familiar é formada por todos esses aspectos interligados, sendo dado um significado e uma interpretação própria em cada contexto familiar. Em que a unidade familiar pode ser formada por diversas conjunturas de ligação afetiva, incluindo ao núcleo familiar, primos, avós, amigos, vizinhos, colegas de trabalho, representantes políticos e religiosos. Nessas relações, as emoções e o contexto familiar são únicos e é criada uma relação de cuidado entre os membros desta Unidade (SZYMANSKY H, 1995).

O nascimento prematuro e a necessidade de hospitalização são experiências desafiadoras que altera a dinâmica e a estrutura familiar, modifica os relacionamentos familiares e os próprios membros familiares (ARAUJO NM, ZANI AV, 2015). Configurando-se como um momento delicado e complexo, que gera na família 
muita frustração e sofrimento; pois, do ponto de vista cultural, esperavam um parto a termo, um bebê saudável e que pudesse sair de alta hospitalar sem nenhuma intercorrência (PROVENZI L, SANTORO E, 2015; LIMA VF, et al., 2017) Em decorrência das mudanças culturais, necessidades econômicas e sociais, o papel dos pais no cuidado aos filhos tem se modificado e hoje, em muitas famílias, a figura paterna divide com a materna os cuidados dos filhos e não mais apenas se responsabiliza pelo provento dos mesmos (BENZIES KM, et al., 2017; LELIS BDB, et al., 2018). Porém, no contexto da hospitalização, o pai tem necessidade de retornar às atividades laborais, enquanto a sua companheira necessita estar presentes na unidade neonatal (SANTANA JO, et al., 2017).

Os pais de bebês prematuros geralmente experimentam a separação de seus filhos e/ou a exclusão de seu papel de cuidadores primários durante 0 atendimento hospitalar de seus filhos, o que pode prejudicar 0 vínculo e o bem-estar psicológico dos pais e de outros membros familiares (AHLQVIST-BJÖRKROTH S, et al., 2017). Algo que pode contribuir para a ocorrência de conflitos, ansiedade e o agravamento da sensação de culpa dos pais, dificultando sua compreensão de que é importante para o seu bebê diante da hospitalização (SANTOS LM, et al., 2013).

Cada membro familiar possui a sua rede social de apoio e é importante identificar a teia de interações estabelecidas frente a uma situação de crise e o modo como as pessoas lidam com a experiência da doença. Onde a dinâmica familiar mostra-se com uma variedade de formas de organização, crenças, valores e práticas que se desenvolve diante das situações que a vida lhes apresenta em busca de adequar ou mesmo solucionar problemas e momentos vivenciados (VIERA CS, et al., 2010).

No cenário em estudo, a família ampliada desenvolve e utiliza diversas estratégias para apoiar a mãe durante a hospitalização, oferecendo apoio por meio de visitas diárias, utilizam palavras de conforto envolvendo fé e esperança e ligações telefônicas diárias, na tentativa de ajudá-las a enfrentar o processo de doença e hospitalização do recém-nascido prematuro (SANTOS LM, et al., 2013).

Além de conhecer e cuidar do RN, é preciso que os profissionais de saúde orientem e compreendam a estrutura e a dinâmica familiar; as redes sociais de apoio que as famílias acessam e que está disponível para que possam planejar uma assistência integral e de acordo com as suas necessidades, visto que esse apoio é um dos fatores responsáveis pela manutenção do equilíbrio da dinâmica familiar.

Muitos profissionais regulam a relação da família com o prematuro por meio de normas e rotinas rígidas e não individualizadas, que dificultam a permanência dos membros familiares no ambiente neonatal, algo visualizado na unidade em estudo. Sendo usual a negação da participação em decisões, o que traz sentimentos de coação, não pertença do filho e de ser a unidade neonatal um espaço dos profissionais (CUSTODIO N, et al., 2016; HE SW, et al., 2018).

Outra forma marcante no estudo foi a presença da espiritualidade que, por sua vez, independente da crença ou prática religiosa de cada ser humano, funciona como fonte de consolo durante o período vulnerável da hospitalização na UTIN. A família busca por uma força superior, para amenizar o sofrimento causado pela hospitalização, através da fé em Deus e na oração, para o controle interno de suas emoções e para vivenciar melhor a experiência de ter um filho prematuro na UTIN (SANTOS LM, et al., 2013; ARAÚJO BBM, et al., 2018).

\section{CONCLUSÂO}

O estudo possibilitou apreender que a assistência neonatal centrada na família ainda é incipiente, necessitando um maior respeito aos direitos humanos e a oferta de uma saúde individual e integral para todos os seus membros. Ressalta-se a necessidade de reforçar as estratégias e redes de apoio aos pais no contexto hospitalar estejam presente no ambiente neonatal; bem como desenvolver um novo olhar para as famílias que vivenciam a prematuridade e a hospitalização, através da implantação do Cuidado Centrado na Família nas unidades neonatais, para que a família ampliada seja incorporada neste contexto de forma significativa e natural. 


\section{AGRADECIMENTOS E FINANCIAMENTO}

Esta é uma pesquisa financiada pela Fundação de Amparo à Pesquisa do Estado da Bahia (FAPESB), edital 003/2017, por meio de bolsa de mestrado.

\section{REFERÊNCIAS}

1. PEREIRA NETO EF, et al. Configurações familiares e implicações para o trabalho em saúde da criança em nível hospitalar. Physis, 2016; 26(3):961-979.

2. BIROLI F. Família: novos conceitos [livro eletrônico]. Coleção o que saber. São Paulo: Fundação Perseu Abramo; 2014. $88 \mathrm{p}$.

3. LIU L, et al. Global, regional, and national causes of child mortality in 2000-13, with projections to inform post-2015 priorities: an updated systematic analysis. The Lancet, 2015; 385 (9966): 430-440.

4. SANTANA JO, et al. Paternal care for hospitalized premature children: maternal representations. Rev baiana enferm, 2017; 31(4):e22310.

5. COSTA R, PADILHA MI. Saberes e práticas no cuidado ao recém-nascido em terapia intensiva em Florianópolis (década de 1980). Esc Anna Nery, 2012; 16(2):247-54.

6. SILVA LJ, et al. Tecnologia e humanização na unidade de terapia intensiva Neonatal: reflexões no contexto do processo saúde-doença. Revista Escola Enfermagem USP, 2009; 43(3): 684-9.

7. BRASIL. Ministério da Saúde. Secretaria de Atenção à Saúde. Departamento de Ações Programáticas Estratégicas. Atenção humanizada ao recém-nascido: Método Canguru: manual técnico. 3. ed. Brasília: Ministério da Saúde, 2017.

8. CUSTÓDIO ZA, et al. Redes sociais de apoio no contexto da prematuridade: perspectiva do modelo bioecológico do desenvolvimento humano. Estudos de Psicologia, 2014; 31(2): 247-255.

9. HENCKEMAIER L, et al. Cuidado transcultural de Leininger na perspectiva dos programas de pós-graduação em enfermagem: revisão integrativa. Revista Ciência \& Saúde, 2014; 7(2): 85-91.

10. BARDIN L. Organização da análise. São Paulo: Edições 70, 2016. 279p.

11. CAMARGO BV, JUSTO AM. Tutorial para uso do Softwere IRAMUTEQ (Interface de R pour les Analyses Multidimensionnelles de Textes et de Questionnaires). Laboratório de Psicologia Social de Comunicação e Cognoção UFSC, 2018.

12. 12 SOUZA MAR, et al. The use of IRAMUTEQ software for data analysis in qualitative research. Rev Esc Enferm USP, 2018; 52: e03353.

13. CUSTODIO N, et al. Alta da unidade de cuidado intensivo neonatal e o cuidado em domicílio: revisão integrativa da literatura. REME rev min enferm, 2013; 17(4):984-91.

14. MORAIS AC, CAMARGO CL. O encontro do caminho metodológico com a Teoria Transcultural do Cuidado. Rio de Janeiro: Bonecker; 2017.177p.

15. VIERA CS, et al. Rede e apoio social familiar no seguimento do recém-nascido pré-termo e baixo peso ao nascer. Rev. Eletr. Enf, 2010;12(1):11-9.

16. SZYMANSKY H. Teorias e "teorias" de famílias. In: Carvalho MCB (Org). A família contemporânea em debate. São Paulo: EDU/Cortez; 1995.

17. ARAUJO NM, ZANI AV. Discursos paternos frente ao nascimento e hospitalização do filho prematuro. Rev Enferm UFPE, 2015; 9(2):604-9.

18. PROVENZI L, SANTORO E. The lived experience of fathers of preterm infants in the Neonatal Intensive Care Unit: a systematic review of qualitative studies. J Clin Nurs, 2015; 24(134):1784-94.

19. LIMA VF, et al. Vivência dos familiares de prematuros internados em unidade de terapia intensiva neonatal. REME rev. min. enferm, 2017;21:e-1026.

20. BENZIES KM, et al. Family Integrated Care (FICare) in Level II Neonatal Intensive Care Units: study protocol for a cluster randomized controlled Trial. Trials, 2017; 18 (1): 467.

21. LELIS BDB, et al. Acolhimento materno no contexto da prematuridade. Rev. Enferm UFPE on line, 2018;12(6):1563-9.

22. AHLQVIST-BJÖRKROTH S, et al. Close Collaboration with Parents intervention to improve parents' psychological well-being and child development: Description of the intervention and study protocol. Behav Brain Res, 2017; 325: 303-310.

23. SANTOS LM, et al. Mudanças familiares decorrentes da hospitalização do prematuro em cuidados intensivos: um estudo com puérperas. Revista Baiana de Enfermagem, 2013; 27(3): 230-238.

24. CUSTODIO N, et al. Interações entre profissionais de saúde e mães de prematuros: influência no cuidado materno. Rev. enferm. UERJ, 2016; 24(1): e11659.

25. HE SW, et al. Impact of family integrated care on infants' clinical outcomes in two children's hospitals in China: a pre-post intervention study. Ital J Pediatr, 2018; 44(1): 65.

26. ARAÚJO BBM, et al. Prática social da enfermagem na promoção do cuidado materno ao prematuro na unidade neonatal. Texto Contexto Enferm, 2018; 27 (4): e2770017. 